\title{
Systemic Immuno-metabolic alterations in chronic obstructive pulmonary disease (COPD)
}

Amit R Agarwal ${ }^{*}$ D, Smita Kadam, Ankita Brahme, Manas Agrawal, Komalkirti Apte, Govinda Narke, Kushal Kekan, Sapna Madas and Sundeep Salvi

\begin{abstract}
Background: Metabolic adaptation in immune cells is necessary to modulate immune cell function as it is intricately coupled with intracellular metabolism. We aimed to characterize the metabolic state of human peripheral blood mononuclear cells (PBMCs) after long-term exposure to tobacco smoke in smokers with preserved lung function and COPD subjects.

Methods: PBMCs were isolated from healthy non-smokers (HNS), healthy smokers (HS) and COPD subjects, cultured and the mitochondrial respiration while utilizing glucose (glycolysis), fatty acids ( $\beta$-oxidation) or pyruvate (direct Krebs' cycle substrate) was measured using the XFp Extracellular Flux Analyzer. Plasma levels of inflammatory cytokines IFN- $\gamma$, IL-17, TNF-a, IL-5, IL-9 and IFN-a were measured using flow cytometry. RAW264.7 cells were exposed to cigarette smoke condensate (CSC) for $1 \mathrm{~h}$ and its effect on cell viability, cellular metabolism and phagocytosis ability were also studied. Patient's data was analyzed using the Mann Whitney $U$ test, whereas Student's $t$ test was performed to analyze the in-vitro data.

Results: PBMCs from COPD subjects showed a significant decrease in extracellular acidification rate (ECAR) while utilizing glucose as compared to HNS (151.9 Vs 215\%). Mitochondrial oxygen consumption rate (OCR) on palmitate or pyruvate was also found to be significantly lower in COPD subjects as compared to HS and a strong positive correlation between palmitate OCR in PBMCs and FEV $(r=0.74, p<0.05)$ and FVC $(r=0.79, p<0.05)$ values in HS was observed. The metabolic shift towards fatty acid metabolism in healthy smokers promoted an inflammatory cytokine response with a greater increase in the levels of IL-5, IL-9 and IFN- $a$ as compared to IFN- $\gamma$, IL-17 and TNF- $a$. In-vitro experiments with RAW 264.7 cells showed similar metabolic alterations and a reduced ability to phagocytose Streptococcus pneumonia and Haemophilus influenza after cigarette smoke exposure in the presence of glucose or palmitate.

Conclusions: These findings indicate a metabolic basis for the inflammatory response in COPD and could suggest a new therapeutic target for controlling the immune response and delaying the onset of disease.

Trial registration: This observational study was retrospectively registered in the Clinical Trails Registry - India (ICMR - NIMS) on 19th January 2018 with the registration number CTRI/2018/01/011441.
\end{abstract}

Keywords: Cigarette smoke, PBMCs, Glucose, Fatty acids, Metabolism

\footnotetext{
* Correspondence: aagarwal@crfindia.com

Molecular Respiratory Research Laboratory, Chest Research Foundation, Sr.

No 15, Marigold Premises, Behind Gold Adlabs, Pune, Pune 411014,

Maharashtra, India
}

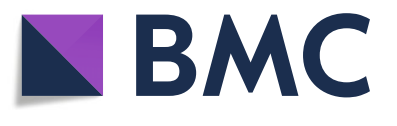

(C) The Author(s). 2019 Open Access This article is distributed under the terms of the Creative Commons Attribution 4.0 International License (http://creativecommons.org/licenses/by/4.0/), which permits unrestricted use, distribution, and reproduction in any medium, provided you give appropriate credit to the original author(s) and the source, provide a link to the Creative Commons license, and indicate if changes were made. The Creative Commons Public Domain Dedication waiver (http://creativecommons.org/publicdomain/zero/1.0/) applies to the data made available in this article, unless otherwise stated. 


\section{Introduction}

COPD is a chronic, progressive disease of the airways and lung parenchyma due to prolonged exposure to noxious particles, including tobacco smoke and is currently estimated to cause 3.2 million deaths every year [1]. COPD is characterized by repeated exacerbations due to recurrent respiratory tract infections and systemic inflammation, thought to be due to overspill of inflammatory mediators from the lungs and/or the entry of noxious particles into the systemic circulation [2]. While the clinical features of systemic inflammation are well recognized, very little is known about the underlying molecular mechanisms that drive it.

Peripheral blood mononuclear cells (PBMCs) comprising of monocytes, lymphocytes and natural killer cells are an important circulating cell population which act as sensors and effectors of metabolic and inflammatory stresses. Glucose and fatty acids are two of the most important substrates utilized by these cells for energy production through glycolysis and $\beta$-oxidation of fatty acids. The acetyl-Co A formed through these mechanisms then enters the Krebs cycle where electrons and co-factors are released which are sequentially transferred from one complex to another through the electron transport chain (ETC) leading to oxidative phosphorylation at Complex V. Energy generation in the absence of oxygen or impairment in the Krebs cycle or ETC in the mitochondria happens through the glycolytic pathway and is limited by the amount of ATP produced. The pyruvate formed in this scenario is converted to lactate and extruded out of the cells which leads to acidification of the extracellular milieu (Fig. 1). PBMCs are known to maintain distinct metabolic profiles during various stages of inflammatory stress $[3,4]$. They respond to environmental cues by orchestrating their metabolic pathways and laying the groundwork necessary to mount [5-7], maintain [8] or resolve inflammatory responses [9]. Naïve and tolerant cells are known to depend on fatty acid oxidation for the generation of energy [9-11], whereas the effector cells are mainly dependent on aerobic glycolysis for the immediate demand of ATP [6, 12] (Fig. 1).

Our previous animal studies have shown that tobacco smoke [13, 14] and its constituents such as acrolein [15] significantly hamper the ability of mouse alveolar type II

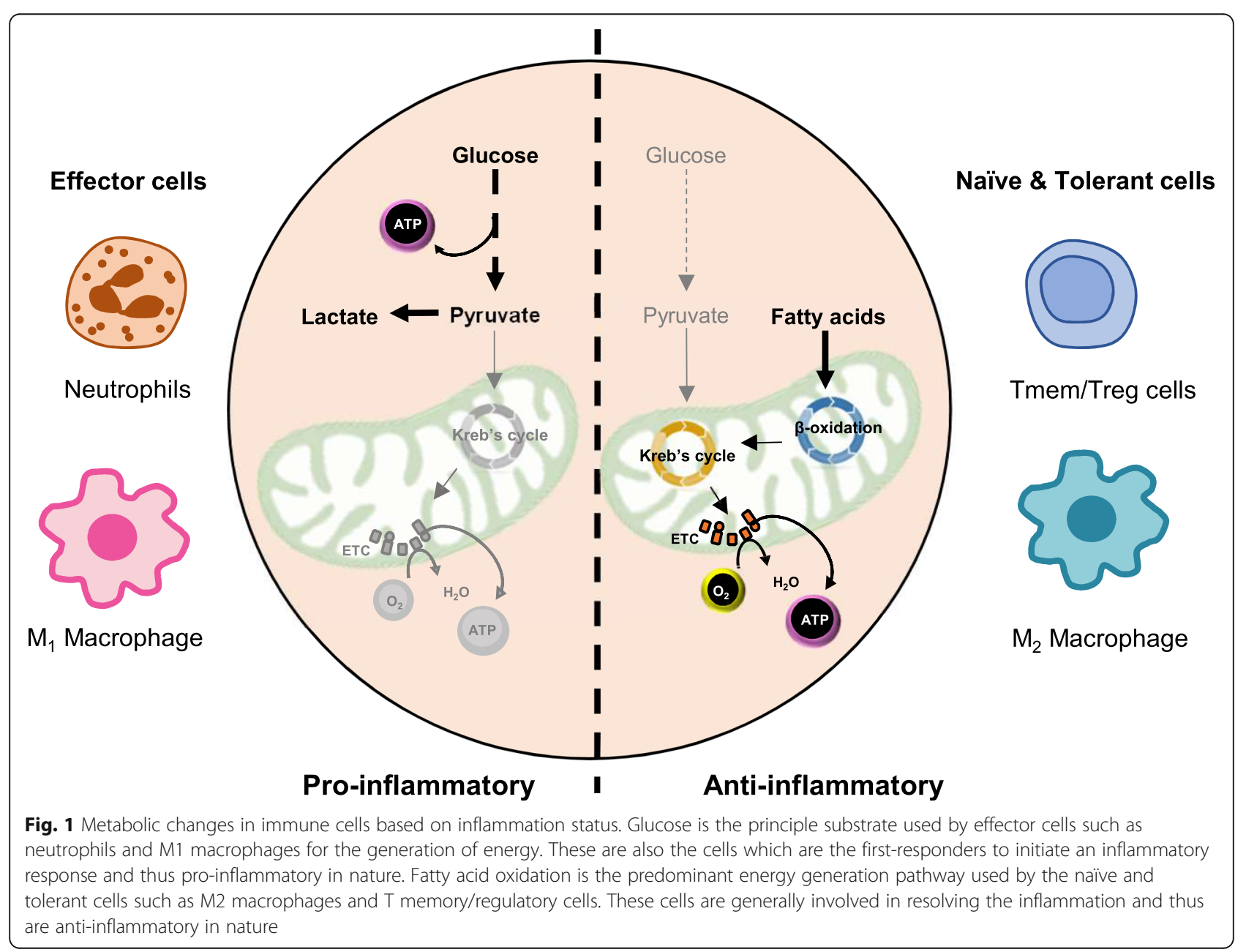


cells to metabolize glucose for the generation of energy. This energy deficit seems to be compensated by increasing the fatty acid metabolism through a genetic up-regulation of $\beta$-oxidation-related genes (Acadl, Acadm, Cpt1a and Slc25a20,13) and supported by the supply of surfactant fatty acids [14] present in the type II alveolar cells. Mitochondria play a central role in this shift because of the localization of all $\beta$-oxidation enzymes in the mitochondrial matrix. These animal studies were performed in mice exposed to cigarette smoke for eight weeks which could not be clinically equated to COPD from an inflammation perspective due to lack of neutrophilic infiltration [13]. The metabolic changes observed in the animal studies could at best be expected in healthy smokers. In COPD, the mitochondrial structure has been found to be altered with fragmentation, branching, and loss of cristae, at least in the bronchial epithelial cells [16]. Airway smooth muscle cells in COPD subjects also showed a loss of mitochondrial membrane potential and decrease in oxygen consumption [17] indicating that mitochondrial dysfunction and deregulated metabolic adaptation may be an important component in COPD pathogenesis [18]. However, mitochondrial dysfunction as a systemic consequence of tobacco smoke exposure in COPD subjects has not been studied before. We hypothesized that long-term exposure to tobacco-smoke would alter the metabolic state of PBMCs and interfere with the immune cell function.

\section{Experimental procedures \\ Participants}

Sixteen healthy non-smokers (HNS), 13 healthy smokers (HS - smokers with normal lung function) and 14 tobacco smoke related COPD patients were recruited at the Chest Research Foundation (Pune, India) along with 11 screen- failures (4 - High fasting blood sugar levels, 2 - probable asthmatics, 2 - hypertension, 2 - could not perform spirometry and 1 - exposure history could not be verified). The screen failure subjects were excluded from any further participation or analysis of their blood samples. COPD was diagnosed on the basis of the history of tobacco smoking (at least ten pack-years) and post-bronchodilator spirometry with $\mathrm{FEV}_{1} / \mathrm{FVC}$ ratio < 0.7 as per the GOLD guidelines. All the participants were above the age of 40 years, and those suffering from other comorbid conditions such as diabetes and hypertension were excluded. Also, participants having a history of any other lung condition such as tuberculosis, asthma, interstitial lung diseases were excluded. All COPD subjects were stable when recruited into the study and free from exacerbations for at least three months. $10 \mathrm{ml}$ of blood was collected through venipuncture, of which one $\mathrm{ml}$ was used for complete blood count analysis. Patients were in a fasting state and the smokers had abstained from smoking for at least 12 $\mathrm{h}$ at the time of blood collection. Plasma samples were stored for inflammatory cytokine analysis. The subjects were informed about their rights associated with their participation in the study along with the risks associated with the procedures. A written informed consent was obtained from all the study participants, and the study was reviewed and approved by the Institutional Ethics Committee of the Chest Research Foundation.

\section{Isolation and culture of PBMCs}

PBMCs were isolated from $9 \mathrm{ml}$ blood samples collected from study participants using the Percoll-density gradient centrifugation method [19]. Briefly, whole blood was added to $5 \mathrm{ml}$ of $6 \%$ Dextran and then diluted with $10 \mathrm{ml} 1 \mathrm{X}$ Hank's Balanced Salt Solution (HBSS). This mixture was allowed to settle in order to sediment the red blood cells. While the blood was sedimenting, gradients were prepared using 55, 67 and $81 \%$ Percoll solution. The supernatant at the top of sedimented blood, containing PBMCs were then transferred to another tube and centrifuged at $350 \mathrm{~g}$ for $10 \mathrm{~min}$. The pellet was resuspended in 55\% Percoll solution and layered above the 81 and $67 \%$ gradient. This gradient solution was then centrifuged again at $350 \mathrm{~g}$ for $30 \mathrm{~min}$ with the PBMCs gathering between the top layer of $55 \%$ Percoll and the middle layer of 67\% Percoll. PBMCs forming a ring between the two layers were then resuspended in 1X HBSS and centrifuged again at $350 \mathrm{~g}$ for $10 \mathrm{~min}$. The resulting cell pellet was resuspended in RPMI1640 supplemented with $5.5 \mathrm{mM}$ glucose, 10\% FBS and then plated in appropriate culture-plates for further assays. The media was not supplemented with any additional nutrients for overnight culture at $37^{\circ} \mathrm{C}$ in $5 \% \mathrm{CO} 2$ incubator. The cells were confirmed to be PBMCs by staining with Diff-Quik stain. All the chemicals required for isolation and culture of PBMCs were procured from Sigma-Aldrich, St. Louis, MO unless specified otherwise.

\section{Extracellular flux analysis}

Freshly isolated PBMCs were plated at a density of 150 , 000 cells/well in the Seahorse XFp cell culture mini plates and allowed to settle overnight. Glucose and pyruvate metabolism was measured in Seahorse base medium, whereas fatty acid metabolism was measured in Krebs-Heinsleit buffer. On the morning of the extracellular flux assay, the culture medium was replaced with Seahorse basal medium without glucose or pyruvate and the cells were starved for $\sim 40 \mathrm{mins}$ till the Xfp plates are calibrated and the cells are incubated in a non- $\mathrm{CO}_{2}$ environment as per the standard Seahorse protocol. The assay protocol was modified to measure initial basal 
respiration (3 readings) and then glucose $(10 \mathrm{mM})$, Palmitate-BSA $(200 \mu \mathrm{M})$ or pyruvate $(2 \mathrm{mM})$ was added through the first port and the change in mitochondrial oxygen consumption rate (OCR) and extracellular acidification rate (ECAR) was measured using the Agilent Seahorse XFp Extracellular Flux Analyzer (Agilent Technologies, USA) as described before [14, 15]. Four micrometer oligomycin was added through the second port to measure the ATP linked respiration. One micrometer FCCP, added through the third port uncoupled the mitochondria and the maximal and spare respiratory capacity were measured. Specific inhibitors in the form of 2deoxyglucose $(50 \mathrm{mM})$, etomoxir $(440 \mu \mathrm{M})$ or rotenone $(1 \mu \mathrm{M})$ was added through the fourth port to inhibit complete mitochondrial respiration on glucose, palmitate or pyruvate, respectively. OCR represents the consumption of oxygen at Complex IV of the ETC while metabolizing glucose/palmitate-BSA/pyruvate. ECAR represents the acidification of the extracellular environment due to formation of lactate (while metabolizing glucose) or carbon dioxide (through the Krebs cycle). The cells were washed $2 \mathrm{X}$ after the OCR and ECAR measurements with $1 \mathrm{X}$ PBS pre-warmed to $37^{\circ} \mathrm{C}$ before measuring the protein concentration using the Bradford Assay to normalize the values.

Palmitate was conjugated with fatty acid-free bovine serum albumin (BSA) by dissolving in $150 \mathrm{mM} \mathrm{NaCl}$ solution at $70^{\circ} \mathrm{C}$ with stirring. The conjugation was performed at $37^{\circ} \mathrm{C}$ in $5 \mathrm{ml}$ aliquots with stirring and unconjugated BSA solution was also used as a control for all the measurements to confirm if the change in OCR was due to palmitate.

RAW264.7 cells were seeded at a density of 40,000 cells per well and the analysis was performed by exposing the cells to CSC in the Seahorse Xfp plates directly, in the presence of complete medium containing glucose and pyruvate. After the CSC exposure for $1 \mathrm{~h}$, the medium was changed to Seahorse basal medium (without glucose and pyruvate) and the plate was incubated in the non- $\mathrm{CO}_{2}$ incubator for $\sim 40$ mins. In order to analyze the response of RAW 264.7 cells to glucose or fatty acids, the substrates were added directly from the first port and the change in ECAR and OCR was measured in real-time, respectively. All values were normalized to the protein concentration in the well after the flux analysis.

Data is represented as percent change in OCR and ECAR in order to compare the response to glucose or fatty acids from multiple subjects and across multiple groups. This percentage change was determined by considering the value just before the addition of substrate (Reading number 3, Additional file 1: Figure S1A, B) as Pre and the highest value reached while after the addition of the substrate (Post). The \% change was determined using the following formula:

$$
\text { \%change }=[(\text { Post }- \text { Pre }) / \text { Pre }] \text { X } 100
$$

ATP-linked respiration was measured as the difference between OCR on oligomycin and OCR on glucose (Additional file 1: Figure S1A) or palmitate. The maximal respiratory capacity was the highest \% change in OCR realized after addition of FCCP and the difference between the maximal respiratory capacity and OCR on glucose (Additional file 1: Figure S1A) or palmitate represented the spare respiratory capacity.

Glycolytic capacity was measured as the maximum ECAR reached after inhibition of mitochondrial respiration (oligomycin) and the difference between the maximum ECAR and the ECAR after addition of glucose was represented as glycolytic reserve capacity. ECAR after addition of 2-DG was considered as the non-glycolytic ECAR (Additional file 1: Figure S1B).

\section{Cytokine analysis}

Plasma samples were collected and stored from one $\mathrm{ml}$ of peripheral blood at $-80^{\circ} \mathrm{C}$. For cytokine analysis, plasma samples were thawed and centrifuged at 10,000 $\mathrm{X} \mathrm{g}$ for $10 \mathrm{~min}$ at $4{ }^{\circ} \mathrm{C}$. The samples were then transferred to a new tube and diluted 8 times for further analysis by flow cytometry using kits available from Mitenyi Biotech, CA, USA as per manufacturers protocol. The assay utilizes capture beads coated with antibodies to specific cytokines. Fluorescence-conjugated secondary antibodies were then utilized against specific cytokines to quantify them using a flow cytometer.

\section{Cell-culture and cigarette smoke exposure}

RAW264.7 cells were obtained from American Type Cell Culture and cultured in Dulbecco's Modified Eagle Medium (DMEM) supplemented with 10\% FBS. Cigarette smoke condensate (CSC) was prepared by pumping cigarette smoke from 4 commercially available cigarettes (Kings Gold Flake, ITC Ltd.) into a condensation apparatus. The resultant condensate was then filtered using $0.2 \mu \mathrm{m}$ membrane filter (Pall Life Sciences, Port Washington, NY). The condensate was standardized spectrophotometrically (Multiskan spectrum, Thermo Scientific, Waltham, MA) by measuring the UV absorbance at $400 \mathrm{~nm}$. Cells were exposed to CSC for 1 $\mathrm{h}$ after which they were washed or scrapped based on further experiments.

\section{Cell viability assay}

Cell viability was measured using 3-(4,5-Dimethylthiazol-2-yl)-2,5-diphenyltetrazolium bromide (MTT) as described previously [15]. RAW264.7 cells were seeded at a density of 80,000 cells per well in a 96-well plate and allowed to settle overnight. Cells were exposed to CSC in media containing glucose $(10 \mathrm{mM})$ and pyruvate 
(2 $\mathrm{mM})$, glucose $(10 \mathrm{mM})$ or palmitate-BSA $(200 \mu \mathrm{M})$ only.

\section{Mitochondrial membrane potential and ROS assays}

Mitochondrial membrane potential was measured using 5,5',6,6' 'tetrachloro-1,1',3,3' -tetraethylbenzimidazolylcarbocyanine iodide (JC-1; Invitrogen, Inc., Waltham, MA). Briefly, RAW264.7 cells were incubated with $10 \mu \mathrm{g} / \mathrm{ml}$ of JC-1 dissolved in sterile warmed PBS after exposure to CSC for $1 \mathrm{~h}$ either in the presence of complete medium or palmitate. The cells were incubated for $10 \mathrm{~min}$ after which they were washed and imaged using a fluorescence microscope (Motic, Hong Kong). $\mathrm{JC}-1$ is a cationic dye which is known to accumulate in the mitochondrial by forming red aggregates whereas the monomeric (green) form remains in the cytoplasm. The ratio of red to green fluorescence was used to indicate the mitochondrial membrane potential. The images were analyzed using ImageJ.

Mitochondrial ROS was measured using MitoSOX Red (Invitrogen, Inc., Waltham, MA). Cells were exposed to CSC either in complete medium or palmitate and then washed with warm sterile PBS. Five micrometer MitoSOX was added to the wells and incubated for $10 \mathrm{~min}$ at $37^{\circ} \mathrm{C}$. The wells were then imaged using the red filter on a fluorescence microscope (Motic, Hong Kong). The images were analyzed using ImageJ.

\section{Phagocytosis assays}

The ability of RAW264.7 cells to phagocytose heat-killed Streptococcus pneumonia and Haemophilus influenza was measured as described previously [20]. Briefly, cells were seeded at a density of 80,000 cells per well overnight and exposed to CSC the next day in complete medium for $1 \mathrm{~h}$. Bacteria were labelled with Alexa Fluor 488 and incubated with cells in the presence of complete medium containing glucose $(10 \mathrm{mM})$ and pyruvate $(2$ $\mathrm{mM})$ ), or glucose $(10 \mathrm{mM})$ or fatty acids (Palmitate-BSA, $200 \mu \mathrm{M})$ only for $3 \mathrm{~h}$ to measure their uptake in the presence of different substrates. The bacteria which was not phagocytosed was removed by washing the wells with warm PBS. The fluorescence emitted from bacteria attached to the cell surface was quenched using trypan blue $(1 \% \mathrm{w} / \mathrm{v})$. The wells were then imaged for internalized bacteria using a fluorescence microscope (Motic, Hong Kong) and analyzed using ImageJ. Cell viability was also measured after the phagocytosis assay to confirm that the change in phagocytosis was not due to changes in cell number.

\section{Glyceraldehyde-3-phosphate dehydrogenase (GAPDH) enzyme activity}

GAPDH enzyme activity was measured in PBMCs and RAW264.7 cells lysed in RIPA buffer supplemented with protease inhibitor as described previously [13, 15]. Briefly, the formation of NADH in the presence of the enzyme (samples) and substrates was monitored using a UV-spectrophotometer at $340 \mathrm{~nm}$.

\section{Statistical analyses}

The demographic data is summarized in Table 1. Normality test (one sample Kolmogorov Smirnov test) was performed for all the parameters before applying any statistical tests. Most of the patient data was non-normally distributed and thus non-parametric tests were used for all the data analysis. One-way ANOVA with post hoc analysis was used to compare mean differences between different study groups, namely HNS, HS and COPD for all the data in Table 1. For non-normally distributed, the non-parametric Kruskal-Wallis test was applied for comparing differences between different study groups. Post-hoc test for non-normally distributed data was performed using Mann-Whitney test. Data is represented by median \pm interquartile range values in the figures and the results section. Correlation between spirometry and metabolic parameters were calculated using Pearson correlation coefficient. Statistical significance was reported at $p<0.05$ level. All the statistical computation was performed using Statistical Package for Social Sciences (SPSS) Version 22.0.

For normally distributed data, Student's $t$ test assuming unequal variances was performed as indicated in the figure legends. Data has been represented by mean \pm standard deviation from a minimum of three experiments.

\section{Results}

The demographic details of 16 healthy non-smokers, 13 healthy smokers and 14 COPD subjects participating in the study are indicated in Table 1. As expected, COPD subjects were older, with a lower BMI and a significantly lower lung function as compared to healthy subjects. The smoking history was well-matched between healthy smokers and COPD subjects. Complete blood count analysis indicated no significant changes in the absolute and percentage count of eosinophils, neutrophils, and lymphocytes between all the three groups. The absolute count (percentage) of monocytes in healthy non-smokers was $435.9 \pm 119$ cells $/ \mu \mathrm{L}(5.7 \pm 0.6 \%)$ which was significantly lower than $595.6 \pm 148.9$ cells/ $\mu \mathrm{L}(7.5 \pm 1.4 \%)$ and $619.4 \pm 224$ cells $/ \mu \mathrm{L}(7.5 \pm 1.6 \%)$ among healthy smokers and smoker COPD subjects, respectively (Table 1).

\section{Impaired glucose metabolism in COPD subjects}

The ability of PBMCs to metabolize glucose was studied by measuring the \% change in OCR and ECAR from baseline (without glucose). PBMCs from COPD subjects $(-0.24 \pm 14.6 \%)$ showed a significantly lower OCR as 
Table 1 Demographic details and baseline characteristics of study participants

\begin{tabular}{|c|c|c|c|c|}
\hline & HNS $(N=16)$ & $\mathrm{HS}(N=13)$ & TS-COPD $(N=14)$ & p-VALUE \\
\hline Age $(Y)$ & $53.38 \pm 10.43$ & $60.15 \pm 8.754$ & $68.36 \pm 8.924$ & $<0.001$ \\
\hline Gender (M/F) & $8 \mathrm{M} / 8 \mathrm{~F}$ & $13 \mathrm{M} / \mathrm{OF}$ & $14 \mathrm{M} / \mathrm{OF}$ & N/A \\
\hline BMI & $24.31 \pm 3.909$ & $23.71 \pm 2.814$ & $19.75 \pm 3.12$ & $<0.01$ \\
\hline Fasting BSL (MG/DL) & $88.63 \pm 12.1$ & $91.54 \pm 16.22$ & $95.31 \pm 11.68$ & NS \\
\hline Smoking history, Pack years (Ex:Current) & N/A & $32.69 \pm 17.37(2: 11)$ & $39.45 \pm 29.98(6: 8)$ & NS \\
\hline $\mathrm{FEV}_{1}$ (\% Predicted) & $104.3 \pm 10.57$ & $97.72 \pm 9.394$ & $51.09 \pm 26.24$ & $<0.001$ \\
\hline FVC (\% Predicted) & $102.3 \pm 13.3$ & $95.08 \pm 11.46$ & $85.85 \pm 20.78$ & $<0.05$ \\
\hline $\mathrm{FVC} / \mathrm{FEV}_{1} \%$ & $102.5 \pm 6.387$ & $103.3 \pm 4.426$ & $58.12 \pm 19.49$ & $<0.001$ \\
\hline COPD gold stage (I/II/III/IV) & N/A & N/A & $3 / 2 / 6 / 3$ & N/A \\
\hline Monocytes (\%) & $5.786 \pm 0.699$ & $7.5 \pm 1.446$ & $7.556 \pm 1.667$ & $<0.01$ \\
\hline (/ML) & $435.9 \pm 119$ & $595.6 \pm 148.9$ & $619.4 \pm 224$ & $<0.05$ \\
\hline Neutrophils (\%) & $55.93 \pm 12.39$ & $53.58 \pm 8.051$ & $60.44 \pm 6.966$ & NS \\
\hline (/ML) & $4186 \pm 1170$ & $4390 \pm 1431$ & $5033 \pm 1656$ & NS \\
\hline Lymphocytes (\%) & $34.43 \pm 10.41$ & $34.83 \pm 7.158$ & $29.11 \pm 5.667$ & NS \\
\hline (/ML) & $2612 \pm 1124$ & $2810 \pm 792.1$ & $2359 \pm 705.4$ & NS \\
\hline Eosinophils (\%) & $3.857 \pm 2.685$ & $4.083 \pm 3.37$ & $2.889 \pm 1.833$ & NS \\
\hline (/ML) & $280.3 \pm 194.4$ & $345.8 \pm 371.1$ & $266.2 \pm 260.8$ & NS \\
\hline
\end{tabular}

Data is represented as mean \pm standard deviation. HNS Healthy non-smokers, HS Healthy smokers and TS-COPD Tobacco-smoking - COPD subjects. ANOVA statistical analysis was performed and $p<0.05$ was considered significant. NS Non-significant and N/A Not applicable

compared to healthy non-smokers $(10.8 \pm 9.3 ; p<0.05)$ (Fig. 2a). ATP production and spare respiratory capacity were found to decrease by $17 \%(p<0.5)$ and $34 \%(p<$ 0.01 ) respectively in HS as compared to HNS (Table 2). PBMCs from COPD patients showed a significant decrease in ATP production, spare and max respiratory capacity by $10 \%(p<0.01), 21 \%(p<0.05)$ and $22 \%(p<$ 0.05 ), respectively as compared to HNS (Table 2) while metabolizing glucose.

The significantly lower levels of ECAR in HS (146.8 \pm $141.9 \%, p<0.5)$ and COPD $(151.9 \pm 77.2 \%, p<0.01)$ patients as compared to HNS $(215 \pm 141.9 \%)$ also indicated a reduced ability to utilize glucose (Fig. 2b). This was further confirmed with a reduced enzyme activity of the glycolytic enzyme; Glyceraldehyde-3-Phosphate Dehydrogenase (GAPDH) in HS $(0.018 \pm 0.022 \mu \mathrm{mol} / \mathrm{min} /$ $\mathrm{mg}$ of protein; $p<0.05)$ and COPD subjects $(0.013 \pm$ $0.016 \mu \mathrm{mol} / \mathrm{min} / \mathrm{mg}$ of protein; $p<0.01$ ) as compared to HNS $(0.046 \pm 0.06 \mathrm{nmol} / \mathrm{min} / \mathrm{mg}$ of protein). COPD patients also showed a significant decrease in maximum glycolytic capacity $(37 \%, p<0.05)$ and the glycolytic reserve $(37 \%, p<0.05)$ and a $29 \%$ increase in non-glycolytic acidification $(p<0.01)$ as compared to healthy nonsmokers (Table 2).

\section{Impaired pyruvate metabolism in COPD subjects} The metabolism of pyruvate which is a direct substrate for the mitochondria, was found to be significantly lower in PBMCs of COPD subjects $(5.9 \pm 8.5 \% ; p<0.05)$ as compared with healthy smokers $(14.9 \pm 23 \%$, Fig. 2a).

\section{Impaired fatty acid metabolism in COPD subjects}

COPD subjects showed a significantly reduced ability to metabolize fatty acids as measured by the \% change in baseline (without Palmitate-BSA) oxygen consumption rate (OCR) after addition of palmitateBSA as compared to healthy smokers $(20.3 \pm 22.1 \%$ Vs $36.9 \pm 16.3 \%$; $p<0.05$ ) (Fig. 2a). The higher rate of fatty acid metabolism in healthy smokers correlated significantly and positively with lung function parameters; $\mathrm{FEV}_{1}(\mathrm{r}=0.74, p<0.05)$ (Fig. 2d) and FVC $(\mathrm{r}=$ $0.79, p<0.05$ ) (Fig. 2e). COPD patients showed a significant decrease in ATP production, spare and max respiratory capacity by $29 \%(p<0.001), 18 \%(p<0.01)$ and $42 \%(p<0.05)$, respectively as compared to HNS (Table 2$)$ and $39 \%(p<0.01), 20 \%(p<0.01)$ and $41 \%$ $(p<0.05)$, respectively as compared to HS while metabolizing palmitate (Table 2).

\section{Inflammatory cytokine response in COPD patients}

Plasma levels of inflammatory cytokines (IFN- $\gamma$, IL-17, TNF- $\alpha$, IL-5, IL-9 and IFN- $\alpha$ ) were measured in the subject population using flow cytometry. The levels of all the inflammatory cytokines; IFN- $\gamma$, IL-17, TNF- $\alpha$, IL-5, IL-9 and IFN- $\alpha$ were significantly elevated in 


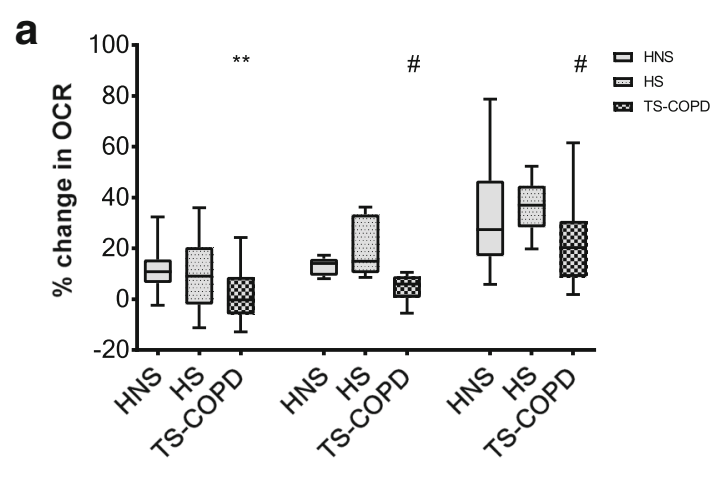

Glucose Pyruvate Fatty acids
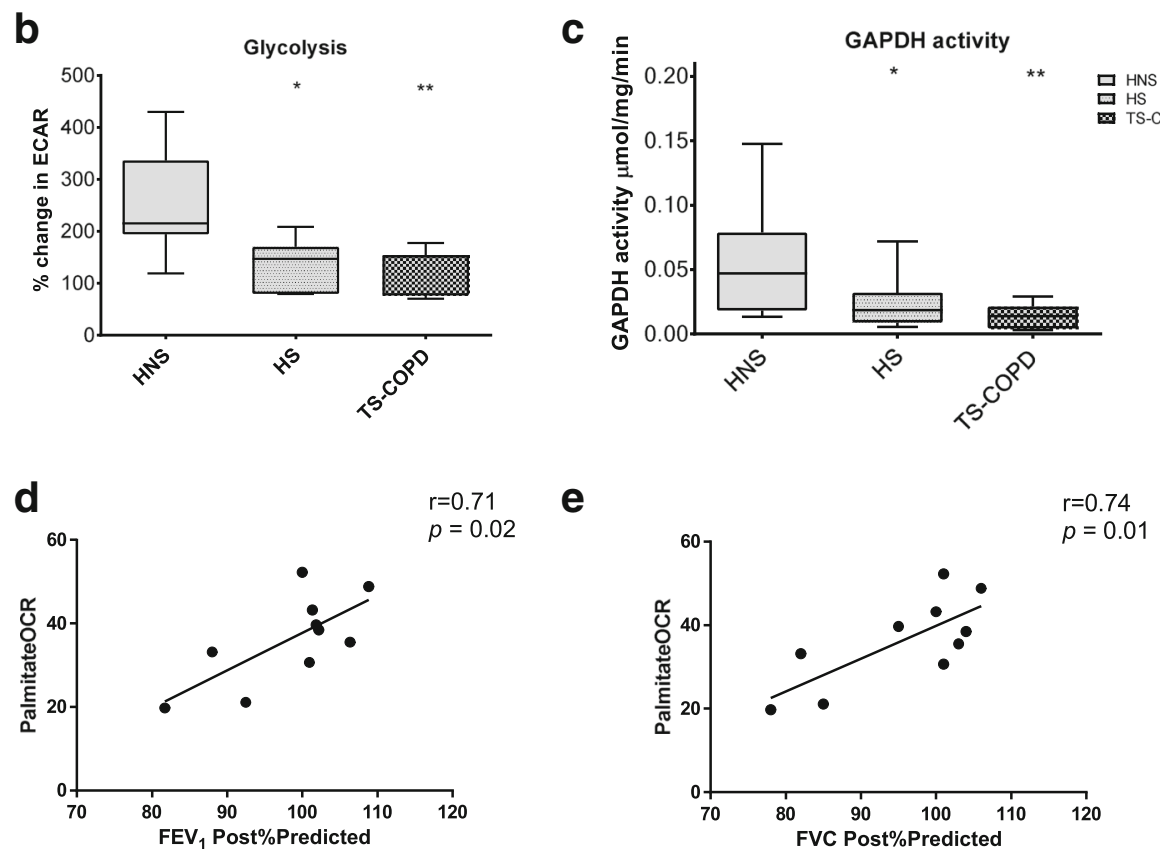

Fig. 2 Defective glycolytic and mitochondrial metabolism in PBMCs of COPD subjects. \% Change in OCR (a) in PBMCs from 16 healthy nonsmokers (HNS), 10 healthy smokers (HS) and 13 tobacco smoking COPD (TS-COPD) subjects while metabolizing glucose (10 mM), pyruvate (2 mM) and palmitate-BSA $(200 \mu \mathrm{M})$ measured using the XF Extracellular Flux analyzer as described in the material and methods section. \% Change in ECAR (b) in PBMCs while metabolizing glucose $(10 \mathrm{mM})$ was measured as described in the material and methods section. c GAPDH enzyme activity measured by monitoring consumption of NAD at $340 \mathrm{~nm}$ in $15 \mathrm{HNS}, 13 \mathrm{HS}$ and 10 TS-COPD subjects. Median values are indicated with a line for each group and ${ }^{*} p<0.05,{ }^{* *} p<0.01$ vs HNS; \# $p<0.05$ Vs HS was considered as statistically significant using the Mann-Whitney U test. Correlation analysis of fatty acid metabolism with lung function parameters showed a strong positive correlation between palmitate OCR and $\mathrm{FEV}_{1}(\mathrm{D})$ and FVC (E) for 10 healthy smokers as shown

COPD subjects as compared to HNS $(p<0.001)$ (Fig. 3a-f). HS subjects also showed a significant increase in all the cytokines as compared to HNS, except IFN- $\gamma$ (Fig. 3a-f).

In COPD subjects, the median fold change in IL-5 2.82, IL-9 -1.96 and IFN- $\alpha-2.25$ was greater than IFN- $\gamma-1.19$, IL-17 - 1.73 and TNF- $\alpha-1.77$ as compared to HNS. Similarly, the median fold change in IL-5 - 2.89, IL-9 - 1.64 and IFN- $\alpha-1.59$ was greater than IFN- $\gamma-0.96$, IL-17 -1.25 and TNF- $\alpha-1.34$ in HS as compared to HNS.

\section{Cigarette smoke induced cellular and mitochondrial toxicity}

The effect of $1 \mathrm{~h}$ CSC exposure on cell viability was studied by measuring the ability of cells to reduce MTT. A dose-dependent decrease was found in cell viability (Fig. 4a) when supplemented with complete medium containing glucose and pyruvate. Cell viability was also found to decrease significantly and in a dosedependent fashion after CSC exposure, when supplemented with glucose alone (Fig. 4b). On the other hand, palmitate supplementation protected the cells against 
Table 2 Effect of electron transport chain complex inhibitors on OCR and ECAR in PBMCs

\begin{tabular}{|c|c|c|c|c|}
\hline & & HNS & HS & TS-COPD \\
\hline \multirow[t]{3}{*}{ Glucose OCR } & ATP Production (\%) & $61.3(56.5-66.2)$ & $50.7(48.6-59.6)^{*}$ & $54.8(48.8-57.3)^{* *}$ \\
\hline & MAX ReSP. Capacity (\%) & $91.9(73.8-109.5)$ & $80.2(51.6-93.8)$ & $72.1(59.0-75.7)^{*}$ \\
\hline & Spare Resp. Capacity (\%) & $87.5(61.6-105.4)$ & $57.1(42.7-69.0)^{* *}$ & $68.0(57.8-77.3)^{*}$ \\
\hline \multirow[t]{3}{*}{ Glucose ECAR } & Glycolytic Capacity (\%) & $315.6(278.7-358.1)$ & $194(170-267.8)$ & $198.2(144.4-219.1)^{*}$ \\
\hline & Glycolytic Reserve (\%) & $92.4(65.8-102.6)$ & $84.3(72.2-110.6)$ & $57.8(49.7-64.5)^{*, \# \#}$ \\
\hline & Non-Glycolytic Acidification (\%) & $73(63.4-80.3)$ & $74.5(65.7-92)$ & $94.4(83.9-99.9)^{* *}$ \\
\hline \multirow[t]{4}{*}{ Palmitate OCR } & ATP Production (\%) & $53.5(47.9-72.4)$ & $62.5(52.7-75.9)$ & $37.7(31.4-45.8)^{* * *}, \# \#$ \\
\hline & Max Resp. Capacity (\%) & $101.6(94.3-118.9)$ & $104.2(98.3-130.7)$ & $83.1(56.3-86.5)^{* *}, \# \#$ \\
\hline & Spare Resp. Capacity (\%) & $66.7(47.6-81.1)$ & $65.3(61.5-95.6)$ & $38.5(32.4-57.1)^{*}, \#$ \\
\hline & Non-fatty acid Mitochondrial Resp. (\%) & $30.8(19.5-42.3)$ & $38.6(30.6-49.5)$ & $37.4(25.6-54.8)$ \\
\hline
\end{tabular}

Data for ATP production, maximum respiratory capacity, spare respiratory capacity, glycolytic capacity and glycolytic reserve is represented as median \% change in OCR/ECAR (Inter-quartile range). Non-glycolytic acidification and non-mitochondrial respiration is represented as percentage of baseline (before adding glucose or palmitate) ECAR and OCR, respectively. HNS Healthy non-smokers, HS Healthy smokers and TS-COPD Tobacco-smoking COPD subjects. * indicates $p<0.05$, ** indicates $p<0.01$ and *** indicates $p<0.001$ as compared to HNS whereas, \# indicates $p<0.05$ and \#\# indicates $p<0.01$ as compared to HS using the MannWhitney $\mathrm{U}$ test for between-group comparison

CSC toxicity at lower concentrations of 0.1 and $0.25 \%$ (Fig. 4b).

Mitochondrial health was studied by measuring the changes in mitochondrial membrane potential and the formation of mitochondrial superoxide after CSC exposure. A dose-dependent mitochondrial membrane depolarization was observed after $1 \mathrm{~h}$ CSC exposure with a $79 \%$ decrease in the ratio of red to green fluorescence after 1\% CSC exposure when supplemented with glucose and pyruvate (Fig. 4c). Palmitate supplementation did not alter the mitochondrial membrane polarization in RAW 264.7 cells after exposure to 0.1 and $0.25 \%$ CSC. However, a $78 \%$ decrease in the ratio of red to green fluorescence was observed after 1\% CSC exposure. Mitochondrial ROS production was also found to be elevated in a dose-dependent manner with increasing concentration of CSC exposure (Fig. 4d). A 114\% increase in fluorescence intensity for MitoSOX Red was observed in RAW 264.7 cells after exposure to 1\% CSC (Fig. 4d) when supplemented with complete media and $101 \%$ increase was observed when supplemented with palmitate (Fig. 4d).

\section{Cigarette smoke induced alterations in cellular metabolism}

Mitochondrial respiration (OCR) was found to decrease significantly in a dose-dependent manner with CSC exposure in the presence of complete medium containing glucose and pyruvate (Fig. 5a). 0.1 and $0.25 \%$ CSC exposure decreased the ECAR while metabolizing glucose by 42.6 and $79.3 \%$, whereas the OCR while metabolizing palmitate did not change significantly (Fig. 5b). 0.5\% CSC exposure decreased glucose ECAR and palmitate OCR by 87 and $95.8 \%$, respectively (Fig. $5 b$ ).
A dose-dependent decrease in GAPDH enzyme activity was observed after $1 \mathrm{~h} \mathrm{CSC}$ exposure. 1\% CSC exposure led to a $71.4 \%$ decrease in GAPDH enzyme activity (Fig. 5c) further confirming the CS-induced inhibition of glucose metabolism.

\section{Cigarette smoke induced alterations in macrophage phagocytosis}

The effect of CSC exposure on S. pneumonia and H. influenza phagocytosis by RAW264.7 macrophages was measured using fluorescence microscopy. A dose-dependent decrease in bacterial internalization was observed with $1 \mathrm{~h}$ CSC exposure (Fig. 6a, b). Supplementing the cells with different substrates for energy production did not alter the ability of RAW264.7 cells to phagocytose S. pneumonia and $H$. influenza.

\section{Discussion}

Immune cells are capable of utilizing both glucose and free fatty acids to generate energy. Pro-inflammatory immune cells generally utilize glucose as the main fuel, whereas anti-inflammatory immune cells predominantly utilize free fatty acids $[6,10,12]$ (Fig. 1). The ability to utilize both these fuels is, therefore, necessary to initiate, maintain and resolve an inflammatory response. In this study, we report for the first time that circulating mononuclear cells of subjects with COPD have a reduced ability to utilize glucose, pyruvate or fatty acids at baseline; while circulating mononuclear cells from healthy smokers with preserved lung function have impaired glycolysis, but preserved pyruvate and fatty acid metabolism. The rate of fatty acid metabolism in healthy smokers correlated positively with lung function parameters. These alterations in immune cell metabolism help in their survival but probably interfere with their 
A

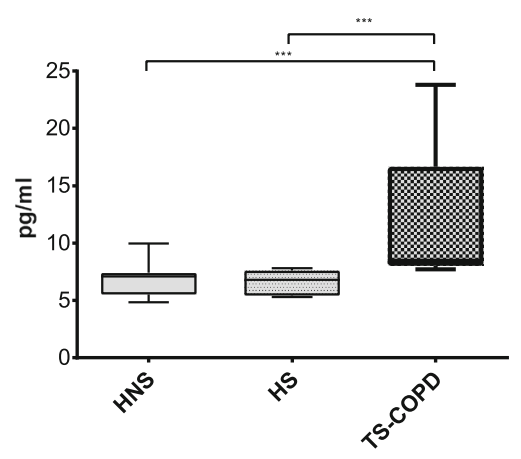

C

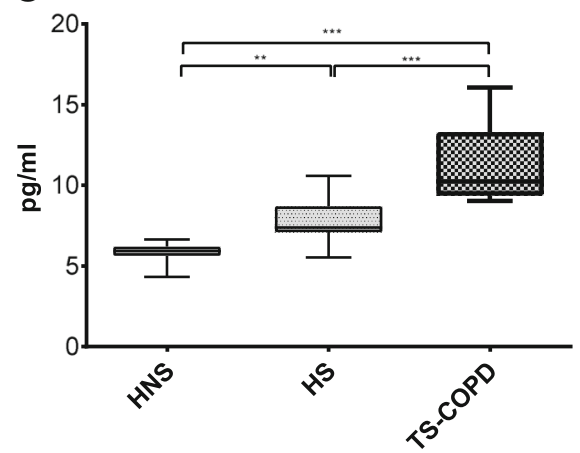

E

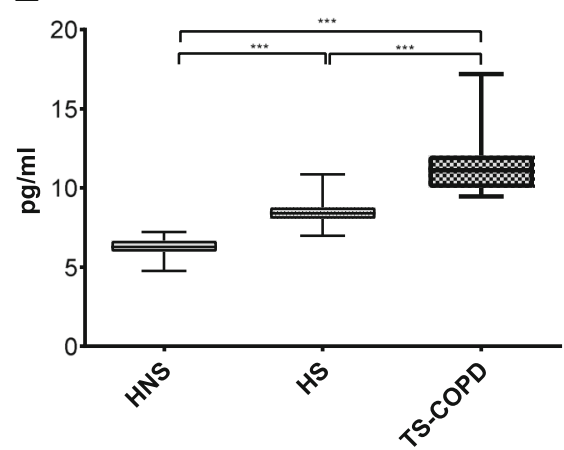

B

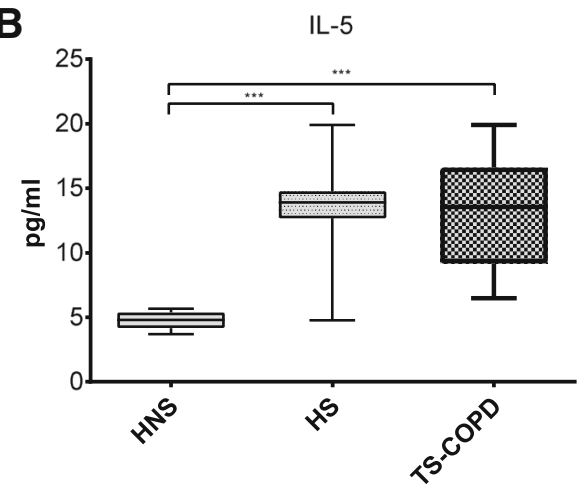

D

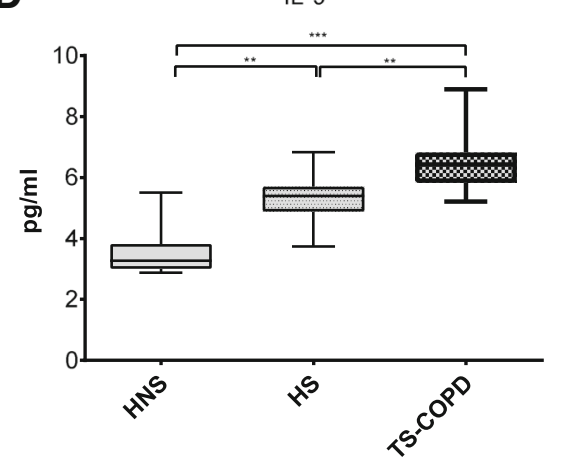

F

IFN- $\alpha$

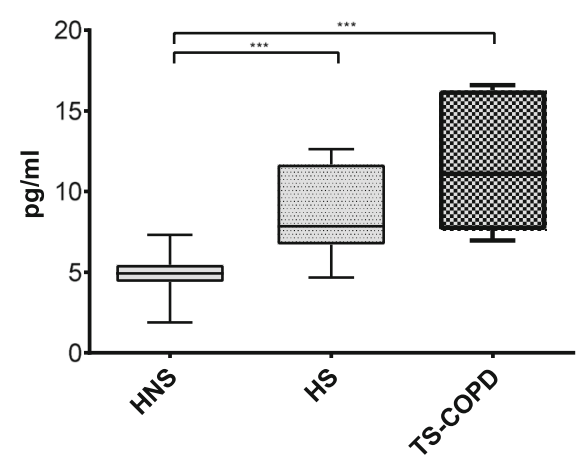

Fig. 3 Changes in plasma inflammatory cytokine levels in healthy smokers and COPD subjects. Plasma cytokine levels of IFN- $\gamma$ (a), IL-5 (b), IL-17 (c), IL-9 (d), TNF-a (e) and IFN-a (f) were measured as described in the material and methods section in 15 HNS, 12 HS and nine TS-COPD subjects. ${ }^{* *} p<0.01$ and ${ }^{* * *} p<0.001$ as compared using the Mann-Whitney $U$ test

function and may be responsible for the type of inflammatory cytokine response in the systemic microenvironment in healthy smokers and COPD patients. These results suggest that an impairment in glycolysis and fatty acid oxidation may play an important role in the pathogenesis of COPD and could be explored as a potential target to delay the onset of disease.

Glucose serves as an important source of energy for immune cells because of its fast metabolism and release of energy [12, 21]. PBMCs from COPD subjects and RAW264.7 cells exposed to CSC were found to have an impaired ability to utilize glucose as indicated by the limited substrate supply in the form of pyruvate to the mitochondria (Fig. 2a), lower rates of extracellular acidification through formation of lactate (Fig. 2b, Fig. 5b) and the decrease in activity of the glycolytic enzyme, GAPDH (Fig. 2c, Fig. 5c). GAPDH is a central glycolytic enzyme with a redox-sensitive cysteine in its active site which is susceptible to oxidative stress-induced posttranslational modification; S-glutathionylation as observed earlier in mice lung cells exposed to CS [13]. The extracellular acidification mainly occurs due to the 


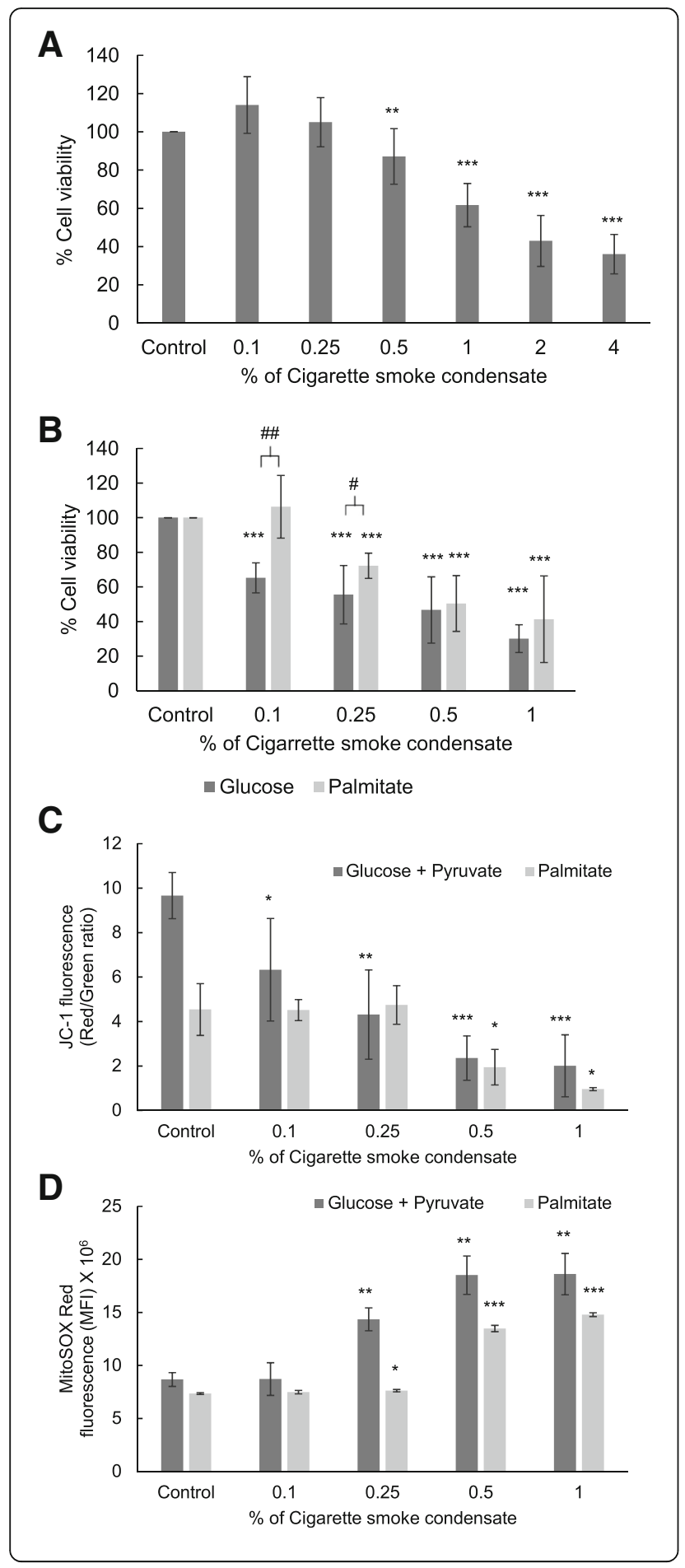

Fig. 4 CSC induced cellular and mitochondrial toxicity in mouse macrophage cells. The cytotoxicity of CSC was studied by measuring the ability of the cells to reduce 3-(4,5-dimethylthiazol-2-yl)-2,5diphenyl tetrazolium bromide (MTT) as described in the material and methods section in the presence of complete medium (glucose and pyruvate, a) or glucose and palmitate-BSA individually (b). Mitochondrial membrane potential was measured using the JC-1 dye after CSC exposure as described in the materials and methods section in the presence of complete medium or palmitate and is expressed as the ratio of red to green fluorescence (c).

Mitochondrial superoxide production was measured using the MitoSOX Red dye after CSC exposure as described in the materials and methods section in the presence of complete medium or palmitate and is expressed as the change in mean fluorescence intensity (MFI) (d). ${ }^{*} p<0.05,{ }^{* *} p<0.01$ and ${ }^{* * *} p<0.001$ as compared to their respective control using the Student's t-test. \# $p<$ 0.05 , and \#\# $p<0.01$ as compared using the Student's $t$-test

protons generated from two sources; glycolysis and tricarboxylic cycle (TCA, $\mathrm{CO}_{2}$ generated is converted to $\mathrm{HCO}_{3}{ }^{-}+\mathrm{H}^{+}$) in the mitochondria [22]. The increase in non-glycolytic acidification in response to addition of 2 'deoxy-glucose (Table 2) indicates a probable increase in $\mathrm{CO}_{2}$ generated from the TCA cycle. This could be supported by an increase in metabolism of residual cellular amino acids such as glutamine or fatty-acids. However, the reduced OCR on palmitate indicates a defect in the ETC which limits the amount of energy generated through these energy sources. Another minor but possible and relatively unexplored source of $\mathrm{CO}_{2}$ is the non-glycolytic breakdown of glucose through the pentose phosphate pathway or the glucoronic acid-xylulose cycle which splits $\mathrm{C}-1$ or $\mathrm{C}-6$ as $\mathrm{CO}_{2}$. A strong glycolytic response is usually considered a hallmark for immune cell activation and for phagocytosis in macrophages, and an impairment in glucose metabolism may predispose these cells from HS and COPD patients to an attenuated immune response and reduced phagocytosis.

The lower rate of fatty acid metabolism in COPD subjects (Fig. 3a) and RAW264.7 cells exposed to higher concentrations of CSC could most likely be due to an inability of the PBMC mitochondria to oxidize fatty acids due to mitochondrial damage. This is supported by the decrease in ATP production, maximum and spare respiratory capacity of PBMC mitochondria from COPD subjects while metabolizing palmitate as compared to HNS and HS (Table 2). A reduced activity of the mitochondrial ETC due to cigarette smoke exposure has also been reported earlier in the PBMCs [23] and lymphocytes [24]. Moreover, an overall reduction in oxygen delivery due to impaired lung function would also make $\beta$-oxidation a challenging task.

The higher rate of fatty acid metabolism in healthy smokers as compared to COPD subjects (Fig. 2a); as also reported by us earlier in mice exposed to CS [14], correlated positively with lung function parameters (Fig. 2d 


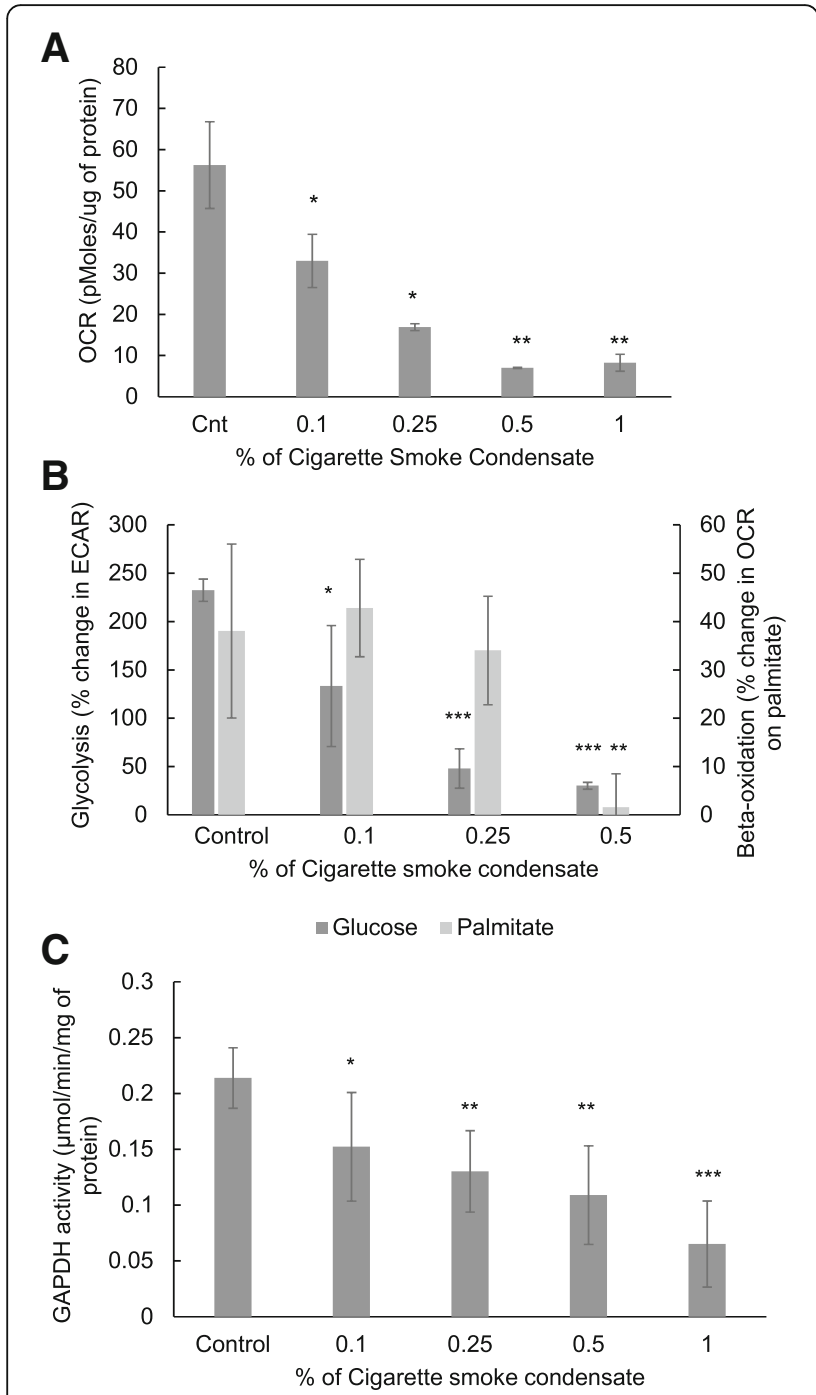

Fig. 5 CS exposure alters cellular metabolism in mouse macrophage cells. \% Change in OCR (a) in RAW 264.7 cells after exposure to CSC for $1 \mathrm{~h}$ in the presence of glucose $(10 \mathrm{mM})$ and puyruvate $(2 \mathrm{mM})$ was measured using the XF Extracellular Flux analyzer as described in the material and methods section. \% Change in OCR (PalmitateBSA, $200 \mu \mathrm{M}$ ) and ECAR (glucose $10 \mathrm{mM}$ )) in RAW 264.7 cells after exposure to CSC for $1 \mathrm{~h}$ (b). GAPDH enzyme activity was measured by monitoring consumption of NAD at $340 \mathrm{~nm}$ in RAW 264.7 cellular lysates after exposure to CSC for $1 \mathrm{~h}$ as described in the materials and methods section (c). ${ }^{*} p<0.05,{ }^{* *} p<0.01$ and ${ }^{* * *} p<0.001$ as compared to their respective control using the Student's $t$-test

and e) suggesting that higher fatty acid metabolism may be a protective mechanism that prevents the development of COPD. As the lung function is known to decline with age, healthy smokers with lower $\mathrm{FEV}_{1}$ [25] and lower fatty acid metabolism could warrant a close follow-up to see if they are more susceptible to developing COPD in the near-term. Previous studies have identified the usefulness of fat-rich diet and higher BMI as protective factors associated with relatively better lung function [26] and mortality [27] outcomes, respectively. Cells supplemented with fatty-acids showed a better ability to respond to CSC-induced stress as indicated by the higher cell-viability which may be attributed to the shift in ATP generation from glucose to fatty acids. Exposure to higher concentrations of CSC damages the mitochondria which may prevent the further utilization of fatty acids as an energy source (Fig. 4b). We found that the membrane potential is maintained (Fig. 4c) and mitochondrial ROS production (Fig. 4d) is not increased even after exposure to $0.25 \%$ of CSC under palmitate supplementation. These data indicate that palmitate supplementation offers an alternative source for energy production and helps to prevent mitochondrial toxicity.

In concordance with our results, Shaykhiev et al. [28] observed a deactivation of the M1-related genes in healthy smokers that primarily depend on glucose along with consequent induction of the M2-related genes that are primarily dependent on fatty acids. Interestingly, CD36, which is involved in the uptake of fatty acids into the cells was one of the M2-related genes which were found to be significantly up-regulated in the healthy smokers [28].

The reduction of OCR and ECAR in COPD PBMCs is most likely because of inhibition of enzymes of the glycolytic and $\beta$-oxidation pathway which may lead to an accumulation of the intermediates within the cells. A number of glycolytic enzymes in immune cells are known to perform non-metabolic functions through signaling and gene regulation that influence the inflammatory response [29]. For eg, GAPDH is known to be translocated to the nucleus under conditions of oxidative stress to initiate apoptosis [30] or induce translation of IFN- $\gamma$ and IL-2 in Tcells under glucose deprived conditions [31]. Alternative pathways in the cytoplasm may also metabolize glucose such as the pentose phosphate pathway (which is also known to be upregulated under oxidative-stress) and glucoronic acid pathway. Unutilized or excess fatty acids may uncouple mitochondrial respiration and induce lipotoxicity if not stored in the form of lipid droplets which act as highly dynamic storage pool of fatty acids to support immune cell activation and function. Similarly, unutilized glucose could also be stored as glycogen within the cells. Thus it could be postulated that, impaired immune cell metabolism may drive disease pathophysiology by altering the immune cell function. As is evident from both, invitro and in-vivo data; mitochondrial health in immune cells play an important role in the progression of COPD (Fig. 2a, Fig. 4b) and could be considered as the driving force in the development of COPD. As long as the mitochondria are healthy, the disease progression is impeded as shown in healthy smokers and RAW 264.7 cells exposed to 0.1 and $0.25 \%$ CSC.

Immunometabolic reprogramming is known to be at the center of an immune response to an inflammatory 

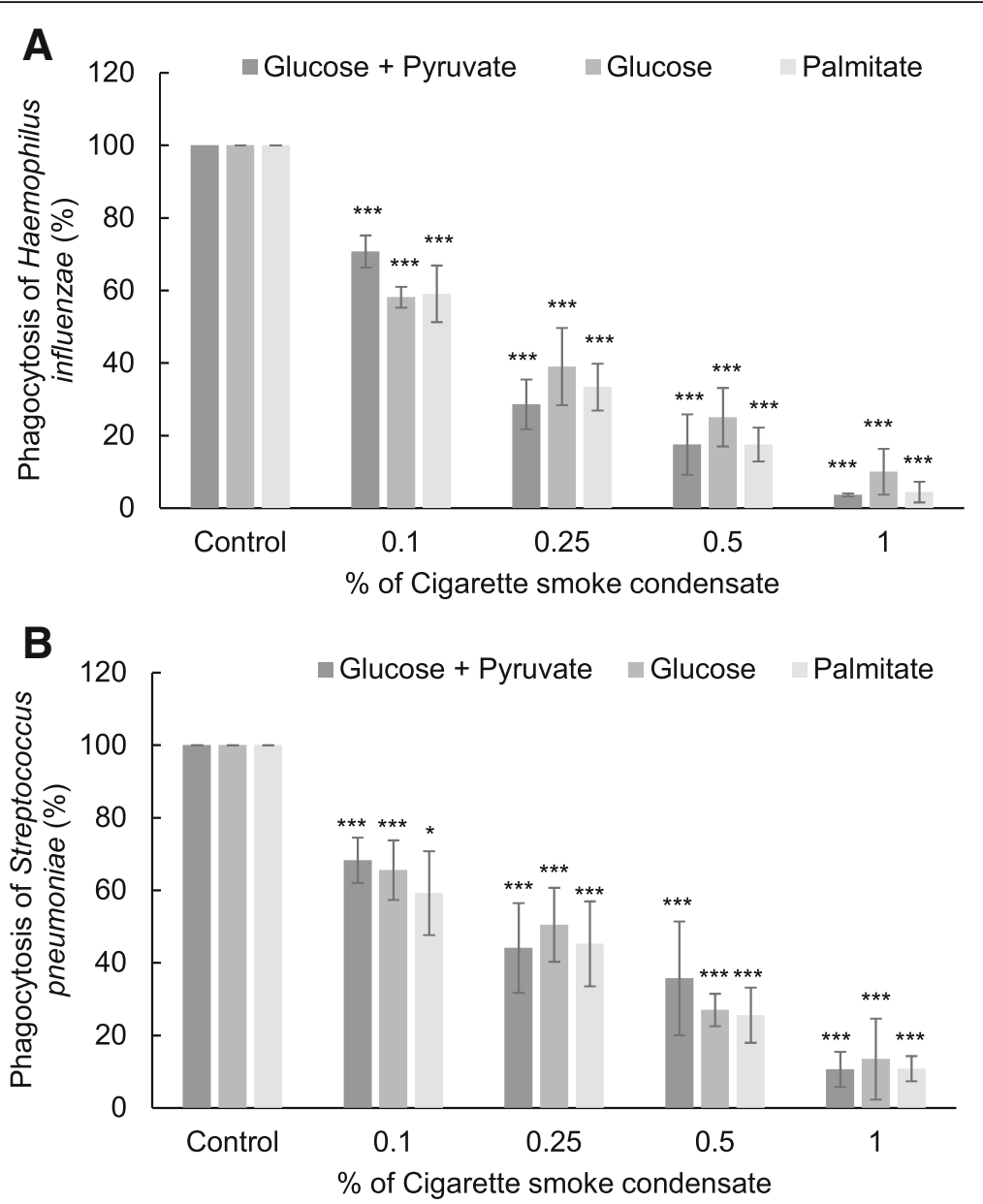

Fig. 6 CS exposure impairs bacterial phagocytosis in mouse macrophage cells. \% Change in internalization of fluorescently labelled $H$. influenza (a) and S. pneumonia (b) by RAW 264.7 cells after exposure to CSC for $1 \mathrm{~h}$ was measured in the presence of glucose (10 mm) and pyruvate (2 Mm), glucose only $(10 \mathrm{Mm})$ or palmitate-BSA $(200 \mu \mathrm{M})$ using a fluorescence microscope. ${ }^{*} p<0.05$ and ${ }^{* * *} p<0.001$ as compared to their respective control using the Student's t-test

stimulus [7, 32]. Glucose metabolism supports the acute response to inflammatory stimuli with the production of instantaneous energy required for immune cells' migration [33] and activation [21]. The anti-inflammatory/ resting state is characterized by a metabolic shift from glucose to fatty acid metabolism in tolerant/naïve cells for energy production $[9,11]$. A number of studies have tried to define the macrophage polarization in COPD patients as either M1 or M2 based on gene expression or cytokine profiles with conflicting results $[28,34,35]$. As cellular metabolism is intricately linked to pro- or anti-inflammatory phenotype of immune cells, we aimed to validate the immune cell phenotype with its metabolic state. This was confirmed in healthy smokers, where the lower rates of glycolysis along with preserved fatty acid metabolism promoted a Th2 type immune response $[10,36]$ as shown by a greater increase in the Th2 cytokines (IL-5 and IL-9) in the plasma (Fig. 3b, d). Th2 cytokines are known to promote the M2 phenotype in macrophages [37, 38] which is primarily dependent on fatty acid metabolism. These findings are consistent with other studies which have shown similarly elevated levels of blood cytokines in COPD patients [39, 40].

Macrophages are an important immune cell population in COPD as they are responsible for initiating and resolving inflammation and maintaining lung homeostasis by clearing the airborne irritants and microbes. Metabolic impairment in these cells has been shown to contribute to the reduced migratory ability seen in COPD patients [41], decreased phagocytosis [42] and the subsequent increase in bacterial load due to reduced clearance [43]. We have recently shown an inability of monocyte-derived macrophages from healthy smokers and COPD patients to phagocytose S. pneumonia and $H$. influenza [20]. Similarly, RAW 264.7 cells also showed a dose-dependent decrease in their ability to internalize S. pneumonia and $H$. influenza after CSC exposure (Fig. 6a, b). The decrease in 
the ability to phagocytose bacteria was not found to be affected by the change in the metabolic substrate for cellular respiration and energy generation. This indicates, that the defect in phagocytosis may be upstream of cellular metabolism and could be related to the non-recognition of the bacteria by the macrophage surface receptors after CS exposure. It could also be surmised that glycolysis is indispensable for bacterial phagocytosis and the metabolic shift towards fatty acid oxidation does not help in bacterial phagocytosis because of the anti-inflammatory phenotype. This could also explain the higher frequency of infections in smokers and COPD subjects.

PBMCs are increasingly being recognized for their role in characterizing the disease pathophysiology largely in inflammatory diseases. Ethical and safety constraints limit the availability of tissue samples from the site of inflammation in a number of diseases. PBMCs are thus being explored as indices/markers of diagnosis and disease monitoring due to their sensory and regulatory role in inflammation. Mitochondrial function in PBMCs is known to be affected in multiple diseases such as diabetic nephropathy [44], systemic lupus erythematous [45], schizophrenia [46], chronic fatigue syndrome [47] and sepsis [48]. PBMCs in patients suffering from sepsis have shown a very similar, generalized defect in both glycolysis and oxidative phosphorylation [48] as observed in COPD subjects here.

As the subjects in two smoke exposed groups (HS and TS-COPD) were all males and the HNS group included males and females, we tested for the possibility of gender bias and found that the results of glucose and fatty acid metabolism are not affected after adjusting for gender differences (data not shown). Most of the COPD subjects were also on therapy and no significant differences in the metabolic parameters were observed between subjects on therapy or not, in the COPD group. The mixture of six ex- and eight current smokers in the COPD group may potentially impact the results but difficult to predict given the small sample size. Previous studies have shown that the inflammatory response in smokers and ex-smokers is more or less similar [49, 50], indicating that ex-smokers also have long-lasting systemic inflammatory responses. Although these factor reflect the characteristics of COPD population in India, these could be suggested as potential limitations to our study.

\section{Conclusion}

In conclusion, our study shows a metabolic impairment in systemic immune cell in subjects with COPD with a reduced ability to metabolize carbohydrate or fatty acids. To the best of our knowledge, this is the first study characterizing these metabolic changes in healthy smokers and COPD subjects. These observations open up new therapeutic opportunities, where specific interventions that can reverse this metabolic impairment (eg. ETC defect) may indeed improve cellular metabolism. The metabolic alterations identified here could explain the reason for frequent exacerbations in COPD subjects and also suggest that drugs that have an ability to reset the metabolic machinery may be potential novel treatment to prevent and treat COPD.

\section{Additional file}

Additional file 1: Figure S1. Representative graph showing change in OCR (A) and ECAR (C) with time after addition of Glucose $(10 \mathrm{mM}$, Port A), Oligomycin (4 $\mathrm{M}$, Port B), FCCP (1 $\mu \mathrm{M}$, Port C) and 2-deoxy-glucose (50 mM, Port D). (PDF $632 \mathrm{~kb}$ )

\section{Abbreviations}

CS: Cigarette smoke; CSC: Cigarette Smoke Condensate; ECAR: Extracellular

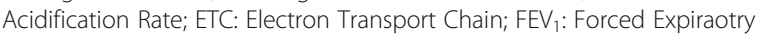
Volume in $1 \mathrm{~s}$; FVC: Forced Vital Capacity; GAPDH: Glyceraldehyde-3-

Phosphate Dehydrogenase; HNS: Healthy non-smokers; HS: Healthy smokers (with preserved lung function); OCR: Oxygen consumption rate;

PBMC: Peripheral Blood Mononuclear Cells; TS-COPD: Tobacco smoke related - Chronic Obstructive Pulmonary Disease

\section{Acknowledgements}

The authors would like to acknowledge the recruitment team led by Renuka Gaikwad and the pulmonary function testing laboratory under Nitin Vanjare for their support in the conduct of the study.

\section{Authors' contributions}

ARA conceptualized and designed the study. SK, AB, MA and KK performed experiments. KA and GN provided the clinical support for subject

classification. ARA and SM analyzed the data. ARA, KA, SK, AB, MA and SS interpreted the results. ARA and SS drafted the manuscript and prepared the figures. ARA and SS approved the final version of the manuscript.

\section{Funding}

The study was funded through internal seed funding from Chest Research Foundation and a research grant from Dept. of Science and Technology, Govt. of India ECR/2017/000950. The funding agency had no role in the design of the study and collection, analysis, and interpretation of data and in writing the manuscript.

\section{Availability of data and materials}

The datasets used and/or analysed during the current study are available from the corresponding author on reasonable request.

Ethics approval and consent to participate

A written informed consent was obtained from all the study participants, and the study was reviewed and approved by the Institutional Ethics

Committee of the Chest Research Foundation.

\section{Consent for publication}

A consent for publication was obtained from all study participants at the time of consenting for participation in the study.

\section{Competing interests}

The authors declare that they have no competing interests.

Received: 5 April 2019 Accepted: 21 July 2019

Published online: 30 July 2019

\section{References}

1. Soriano JB, Abajobir AA, Abate KH, Abera SF, Agrawal A, Ahmed MB, et al. Global, regional, and national deaths, prevalence, disability-adjusted life years, and years lived with disability for chronic obstructive pulmonary 
disease and asthma, 1990-2015: a systematic analysis for the global burden of disease study 2015. Lancet Respir Med. 2017;5(9):691-706.

2. Sinden NJ, Stockley RA. Systemic inflammation and comorbidity in COPD: a result of "overspill" of inflammatory mediators from the lungs? Review of the evidence. Thorax. 2010;65(10):930-6.

3. Liu TF, Vachharajani VT, Yoza BK, McCall CE. NAD(+)-dependent Sirtuin 1 and 6 proteins coordinate a switch from glucose to fatty acid oxidation during the acute inflammatory response. J Biol Chem. 2012;287(31):2575869 Available from: http://www.ncbi.nlm.nih.gov/pmc/articles/PMC3406663/.

4. Chacko BK, Kramer PA, Ravi S, Johnson MS, Hardy RW, Ballinger SW, et al. Methods for defining distinct bioenergetic profiles in platelets, lymphocytes, monocytes, and neutrophils, and the oxidative burst from human blood. Lab Investig. 2013;93:690Available from:. https://doi.org/1 0.1038/labinvest.2013.53.

5. Suzuki H, Hisamatsu T, Chiba S, Mori K, Kitazume MT, Shimamura K, et al. Glycolytic pathway affects differentiation of human monocytes to regulatory macrophages. Immunol Lett. 2016;176:18-27 Available from: http://www.sciencedirect.com/science/article/pii/S0165247816300852.

6. Izquierdo E, Cuevas VD, Fernández-Arroyo S, Riera-Borrull M, Orta-Zavalza E, Joven J, et al. Reshaping of human macrophage polarization through modulation of glucose catabolic pathways. J Immunol. 2015;195(5):2442 LP451 Available from: http://www.jimmunol.org/content/195/5/2442.abstract.

7. Lachmandas E, Boutens L, Ratter JM, Hijmans A, Hooiveld GJ, Joosten $L A B$, et al. Microbial stimulation of different toll-like receptor signalling pathways induces diverse metabolic programmes in human monocytes. Nat Microbiol. 2016;2:16246Available from:. https://doi.org/10.1038/ nmicrobiol.2016.246.

8. Michelucci A, Cordes T, Ghelfi J, Pailot A, Reiling N, Goldmann O, et al. Immune-responsive gene 1 protein links metabolism to immunity by catalyzing itaconic acid production. Proc Natl Acad Sci. 2013;110(19):7820 LP7825 Available from: http://www.pnas.org/content/110/19/7820.abstract.

9. Huang SC-C, Everts B, Ivanova Y, O'Sullivan D, Nascimento M, Smith AM, et al. Cell-intrinsic lysosomal lipolysis is essential for macrophage alternative activation. Nat Immunol. 2014;15(9):846-55 Available from: http://www.ncbi. nlm.nih.gov/pmc/articles/PMC4139419/.

10. Angela M, Endo Y, Asou HK, Yamamoto T, Tumes DJ, Tokuyama H, et al. Fatty acid metabolic reprogramming via mTOR-mediated inductions of PPARy directs early activation of T cells. Nat Commun. 2016;7:13683Available from:. https://doi.org/10.1038/ncomms13683.

11. Pan Y, Tian T, Park CO, Lofftus SY, Mei S, Liu X, et al. Survival of tissueresident memory $T$ cells requires exogenous lipid uptake and metabolism. Nature. 2017;543(7645):252-6.

12. Borregaard N, Herlin T. Energy metabolism of human neutrophils during phagocytosis. J Clin Invest. 1982;70(3):550-7 Available from: http://www. ncbi.nlm.nih.gov/pmc/articles/PMC370256/.

13. Agarwal AR, Zhao L, Sancheti H, Sundar IK, Rahman I, Cadenas E. Short-term cigarette smoke exposure induces reversible changes in energy metabolism and cellular redox status independent of inflammatory responses in mouse lungs. Am J Physiol Lung Cell Mol Physiol. 2012;303(10):L889-98 Available from: http://www.ncbi.nlm.nih.gov/pubmed/23064950.

14. Agarwal AR, Yin F, Cadenas E. Short-term cigarette smoke exposure leads to metabolic alterations in lung alveolar cells. Am J Respir Cell Mol Biol. 2014; 51(2):284-93.

15. Agarwal AR, Yin F, Cadenas E. Metabolic shift in lung alveolar cell mitochondria following acrolein exposure. Am J Physiol Lung Cell Mol Physiol. 2013;305(10):L764-73 Available from: http://www.ncbi.nlm.nih.gov/ pubmed/24056970.

16. Hoffmann RF, Zarrintan S, Brandenburg SM, Kol A, de Bruin HG, Jafari S, et al. Prolonged cigarette smoke exposure alters mitochondrial structure and function in airway epithelial cells. Respir Res. 2013;14(1):97 Available from: http://respiratory-research.com/content/14/1/97.

17. Hara H, Araya J, Ito S, Kobayashi K, Takasaka N, Yoshii Y, et al. Mitochondrial fragmentation in cigarette smoke-induced bronchial epithelial cell senescence. Am J Physiol Lung Cell Mol Physiol. 2013; 305(10):L737-46 Available from: http://ajplung.physiology.org/cgi/doi/1 0.1152/ajplung.00146.2013.

18. Michaeloudes C, Bhavsar PK, Mumby S, Chung KF, Adcock IM. Dealing with stress: defective metabolic adaptation in chronic obstructive pulmonary disease pathogenesis. Ann Am Thorac Soc. 2017;14:S374-82.

19. Ilott NE, Heward JA, Roux B, Tsitsiou E, Fenwick PS, Lenzi L, et al. Long noncoding RNAs and enhancer RNAs regulate the lipopolysaccharide-induced inflammatory response in human monocytes. Nat Commun. 2014;5:3979 Available from: http://www.ncbi.nlm.nih.gov/pubmed/24909122.

20. Ghosh B, Gaike AH, Pyasi K, Brashier B, Das W, Londhe JD, et al. Bacterial load and defective monocyte-derived macrophage bacterial phagocytosis in biomass-smoke COPD. Eur Respir J. 2018;53(2). In press.

21. Macintyre AN, Gerriets VA, Nichols AG, Michalek RD, Rudolph MC, Deoliveira $D$, et al. The glucose transporter Glut1 is selectively essential for CD4 T cell activation and effector function. Cell Metab. 2014;20(1):61-72 Available from: http://www.ncbi.nlm.nih.gov/pmc/articles/PMC4079750/.

22. Mookerjee SA, Nicholls DG, Brand MD. Determining maximum glycolytic capacity using extracellular flux measurements. Zhang J, editor. PLoS One. 2016;11(3):e0152016. Available from: https://doi.org/10.1371/journal. pone.0152016

23. Alonso JR, Cardellach F, Casademont J, Miró Ò. Reversible inhibition of mitochondrial complex IV activity in PBMC following acute smoking. Eur Respir J. 2004;23(2):214-8.

24. Miró Ò, Alonso JR, Jarreta D, Casademont J, Urbano-Márquez Á, Cardellach $F$, et al. Smoking disturbs mitochondrial respiratory chain function and enhances lipid peroxidation on human circulating lymphocytes. Carcinogenesis. 1999;20(7):1331-6 Available from: http://www.ncbi.nlm.nih. gov/pubmed/10383908.

25. Masuko H, Sakamoto T, Kaneko Y, lijima H, Naito T, Noguchi E, et al. Lower FEV 1 in non-COPD, nonasthmatic subjects: association with smoking, annual decline in FEV 1, total IgE levels, and TSLP genotypes. Int J COPD. 2011:6(1):181-9.

26. Cai B, Zhu Y, Ma Y, Xu Z, Zao Y, Wang J, et al. Effect of supplementing a high-fat, low-carbohydrate enteral formula in COPD patients. Nutrition. 2003;19(3):229-32.

27. Guo $Y$, Tianyi $Z$, Wang Z, Feifei $Y$, Qin $X$, Wei $G$, et al. Body mass index and mortality in chronic obstructive pulmonary disease: a meta-analysis. PLoS One. 2012;7(8):8

28. Shaykhiev R, Krause A, Salit J, Strulovici-Barel Y, Harvey B-G, O'Connor TP, et al. Smoking-dependent reprogramming of alveolar macrophage polarization: implication for pathogenesis of COPD. J Immunol. 2009;183(4):2867-83 Available from: http:/www.ncbi.n/m.nih.gov/pmc/articles/PMC2873685/.

29. Seki SM, Gaultier A. Exploring non-metabolic functions of glycolytic enzymes in immunity. Front Immunol. 2017;8 Available from: http://journal. frontiersin.org/article/10.3389/fimmu.2017.01549/full.

30. Hara MR, Agrawal N, Kim SF, Cascio MB, Fujimuro M, Ozeki Y, et al. Snitrosylated GAPDH initiates apoptotic cell death by nuclear translocation following Siah1 binding. Nat Cell Biol. 2005;7:665-74 Available from: http:// www.ncbi.nlm.nih.gov/entrez/query.fcgi?cmd=Retrieve\&db=PubMed\&dopt= Citation\&list_uids $=15951807$.

31. Chang CH, Curtis JD, Maggi LB Jr, Faubert B, Villarino AV, O'Sullivan D, et al. Posttranscriptional control of T cell effector function by aerobic glycolysis. Cell. 2013;153(6):1239-51 Available from: http://www.ncbi.nlm.nih.gov/ pubmed/23746840.

32. Arts RJW, Novakovic B, ter Horst R, Carvalho A, Bekkering S, Lachmandas E, et al. Glutaminolysis and fumarate accumulation integrate Immunometabolic and epigenetic programs in trained immunity. Cell Metab. 2016;24(6):807-19 Available from: http://www.sciencedirect.com/ science/article/pii/S1550413116305393.

33. D'Silva H, Gothoskar BP, Jain VK, Advani SH. Cell migration and energy generating metabolic activities. Eur J Cancer. 1978;14(11):1243-8 Available from: http://www.sciencedirect.com/science/article/pii/0014296478902311.

34. Eapen MS, Hansbro PM, McAlinden K, Kim RY, Ward C, Hackett TL, et al. Abnormal M1/M2 macrophage phenotype profiles in the small airway wall and lumen in smokers and chronic obstructive pulmonary disease (COPD). Sci Rep. 2017;7(1):13392.

35. Lyamina S, Malyshev I. Imbalance of immune response functional phenotype and alveolar macrophages phenotype in COPD. Eur Respir J. 2014;44(Suppl 58):P1483 Available from: http://erj.ersjournals.com/ content/44/Suppl_58/P1483.abstract.

36. Nobs SP, Natali S, Pohlmeier L, Okreglicka K, Schneider C, Kurrer M, et al. PPARY in dendritic cells and T cells drives pathogenic type-2 effector responses in lung inflammation. J Exp Med. 2017;214(10):3015-35 Available from: http://www.jem.org/lookup/doi/10.1084/jem.20162069.

37. Stein M, Keshav S, Harris N, Gordon S. Interleukin 4 potently enhances murine macrophage mannose receptor activity: a marker of alternative immunologic macrophage activation. J Exp Med. 1992;176(1):287-92 Available from: http://www.ncbi.nlm.nih.gov/pubmed/1613462. 
38. Gordon S, Martinez FO. Alternative activation of macrophages: mechanism and functions. Immunity. 2010;32(5):593-604 Available from: https:// linkinghub.elsevier.com/retrieve/pii/S1074761310001731.

39. Selvarajah S, Todd I, Tighe PJ, John M, Bolton CE, Harrison T, et al. Multiple circulating cytokines are Coelevated in chronic obstructive pulmonary disease. Mediat Inflamm. 2016;2016:1-9 Available from: http://www.hindawi. com/journals/mi/2016/3604842/.

40. Garcia-Rio F, Miravitlles M, Soriano JB, Muñoz L, Duran-Tauleria E, Sánchez G, et al. Systemic inflammation in chronic obstructive pulmonary disease: a population-based study. Respir Res. 2010;11(1):63 Available from: http:// respiratory-research.biomedcentral.com/articles/10.1186/1465-9921-11-63.

41. Ravi AK, Plumb J, Gaskell R, Mason S, Broome CS, Booth G, et al. COPD monocytes demonstrate impaired migratory ability. Respir Res. 2017;18:90 Available from: http://www.ncbi.nlm.nih.gov/pmc/articles/PMC5425971/.

42. Taylor AE, Finney-Hayward TK, Quint JK, Thomas CMR, Tudhope SJ, Wedzicha JA, et al. Defective macrophage phagocytosis of bacteria in COPD. Eur Respir J. 2010;35(5):1039-47 Available from: http://erj.ersjournals. com/content/35/5/1039.abstract.

43. Wang $H$, Gu $X$, Weng $Y, X u T$, Fu Z, Peng $W$, et al. Quantitative analysis of pathogens in the lower respiratory tract of patients with chronic obstructive pulmonary disease. BMC Pulm Med. 2015;15(1):94Available from. https://doi. org/10.1186/s12890-015-0094-z.

44. Czajka A, Ajaz S, Gnudi L, Parsade CK, Jones P, Reid F, et al. Altered mitochondrial function, mitochondrial DNA and reduced metabolic flexibility in patients with diabetic nephropathy. EBioMedicine. 2015;2(6):499-512.

45. Lee $\mathrm{H}-\mathrm{T}$, Lin $\mathrm{C}-\mathrm{S}$, Pan S-C, Wu T-H, Lee C-S, Chang D-M, et al. Alterations of oxygen consumption and extracellular acidification rates by glutamine in PBMCs of SLE patients. Mitochondrion. 2018; Available from: https:// linkinghub.elsevier.com/retrieve/pii/S1567724917301952.

46. Liu M-LL, Zhang X-XT, Du X-XY, Fang Z, Liu Z, Xu Y, et al. Severe disturbance of glucose metabolism in peripheral blood mononuclear cells of schizophrenia patients: a targeted metabolomic study. J Transl Med. 2015;13(1):226 Available from: http://www.translational-medicine.com/ content/13/1/226.

47. Tomas C, Brown A, Strassheim V, Elson J, Newton J, Manning P. Cellular bioenergetics is impaired in patients with chronic fatigue syndrome. PLoS One. 2017;12(10):e0186802.

48. Cheng SC, Scicluna BP, Arts RJW, Gresnigt MS, Lachmandas E, GiamarellosBourboulis EJ, et al. Broad defects in the energy metabolism of leukocytes underlie immunoparalysis in sepsis. Nat Immunol. 2016;17(4):406-13.

49. Serapinas D, Narbekovas A, Juskevicius J, Sakalauskas R. Systemic inflammation in COPD in relation to smoking status. Multidiscip Respir Med. 2011;6(4):214 Available from: http://mrmjournal.biomedcentral.com/articles/1 0.1186/2049-6958-6-4-214.

50. Gamble E, Grootendorst DC, Hattotuwa K, O'Shaughnessy T, Ram FSF, Qiu Y, et al. Airway mucosal inflammation in COPD is similar in smokers and exsmokers: a pooled analysis. Eur Respir J. 2007;30(3):467-71.

\section{Publisher's Note}

Springer Nature remains neutral with regard to jurisdictional claims in published maps and institutional affiliations.

Ready to submit your research? Choose BMC and benefit from:

- fast, convenient online submission

- thorough peer review by experienced researchers in your field

- rapid publication on acceptance

- support for research data, including large and complex data types

- gold Open Access which fosters wider collaboration and increased citations

- maximum visibility for your research: over $100 \mathrm{M}$ website views per year

At BMC, research is always in progress.

Learn more biomedcentral.com/submissions 